\title{
Perioperative Lumbar Drain Placement: An Independent Predictor of Tension Pneumocephalus and Intracranial Complications Following Anterior Skull Base Surgery
}

\author{
Jon-Paul Pepper, MD; Erin M. Lin, MD, FACS; Stephen E. Sullivan, MD; \\ Lawrence J. Marentette, MD, FACS
}

\begin{abstract}
Objective: To measure the effect of routine perioperative lumbar drain placement during anterior skull base surgery on the frequency of: 1) tension pneumocephalus and 2) total intracranial complications.

Design: Retrospective review of a series of patients $(n=161)$ who underwent the transglabellar/subcranial approach to lesions of the anterior skull base between December 1995 and November 2009. A retrospective cohort (n $=45$ ) underwent routine lumbar drain placement at the time of skull base surgery. The remainder of the series did not undergo routine perioperative lumbar drain placement.

Intervention: Transglabellar/subcranial surgical approach to the anterior skull base, with or without routine perioperative lumbar drain placement.

Results: Routine placement of perioperative lumbar drains was an independent predictor of tension pneumocephalus $(P$ $=.022$, odds ratio $=11.22[1.218-103.3])$. In addition, this practice was also associated with an increased risk of intracranial complications overall $(P=.025$, odds ratio $=2.623[1.104-6.233])$.

Conclusion: Routine placement of perioperative lumbar drain may be associated with an increased risk of tension pneumocephalus and intracranial complications during surgery of the anterior cranial base.

Key Words: Cranial base.

Level of Evidence: $2 b$.
\end{abstract}

Laryngoscope, 121:468-473, 2011

\section{INTRODUCTION}

Surgery of the anterior cranial base has enjoyed progressive refinement and improved outcomes over the past 50 years. ${ }^{1,2}$ Despite considerable advances, these cases are associated with an appreciable rate of both major and minor perioperative complications. ${ }^{3-9}$ One of the most feared complications of anterior skull base surgery is tension pneumocephalus. Accumulation of mixed atmospheric gases exerts a mass-like effect on the adjacent parenchyma, and may lead to permanent neurologic injury or death via transtentorial herniation. ${ }^{10}$ Although a rare complication of anterior skull base surgery, it has been consistently reported in large series, with rates ranging from approximately $1 \%$ to $7 \% .^{3-9}$ True tension pneumocephalus must be distinguished from postopera-

From the Department of Otolaryngology-Head and Neck Surgery (J.P.P., E.M.L., L.J.M.), and Department of Neurosurgery (s.E.s.), University of Michigan Hospital System, Alfred Taubman Health Care Center, Ann Arbor, Michigan, U.S.A.

Editor's Note: This Manuscript was accepted for publication October 7,2010

The authors have no financial disclosures for this article.

The authors have no conflicts of interest to disclose.

Send correspondence to: Dr. Jon-Paul Pepper, Department of Otolaryngology-Head and Neck Surgery, University of Michigan Hospita System, AlfredTaubmanHealth Care Center, 1500 East Medical Center Drive, Floor 1 Reception: A, Ann Arbor, MI 48109-5312.

E-mail: jonpaul@umich.edu

DOI: 10.1002/lary.21409 tive intracranial air accumulation, which is not associated with neurologic injury and may have unique radiographic features. ${ }^{11,12}$ Authors have postulated that the predisposing factors to tension pneumocephalus may include sneezing, coughing, or straining in the early postoperative period, particularly when the flow of air has not been diverted from the skull base. ${ }^{10,13,14}$ There is to date no firm consensus on the matter, as some groups feel that airway diversion has little relation to tension pneumocephalus rates. ${ }^{15}$ Additionally, continuous cerebrospinal fluid (CSF) diversion via lumbar drain, dural involvement of the anterior skull base tumor, and inadequate dural repair have been implicated in the pathogenesis. ${ }^{9,10}$

Placement of a perioperative lumbar catheter is controversial. Theoretical benefits of continuous drainage of CSF via the lumbar drain include dural decompression to facilitate frontal lobe retraction for tumor excision ${ }^{6,7}$ and potential decrease in rates of CSF leak, as reported for surgery in the posterior cranial fossa. ${ }^{16}$ Some authors have postulated that it may minimize the risk of CSF leak following anterior skull base surgery. ${ }^{6,7}$ Unfortunately, these theoretic advantages have counterbalancing presumed risks. However, there is a paucity of strong data regarding the routine placement of perioperative lumbar drains when approaching the anterior skull base. There are many reports in the literature describing tension pneumocephalus in the 
setting of anterior skull base surgery, but there are few statistical analyses that seek to identify which perioperative factors may increase the risk of this possibly preventable complication. ${ }^{13,17}$ Some institutions insert them routinely after induction of general anesthesia, others place a lumbar catheter only for resection of tumors that invade the dura. Therefore, there are no cohort analyses that have estimated the risk of complication following routine lumbar catheter placement in this unique patient population.

The subcranial/transglabbellar approach, as originally described by Raveh, has been employed as the workhorse surgical approach for resection of anterior skull base lesions for over 17 years at our institution. 9,18,19 An initial review of clinical outcomes following the subcranial/ transglabellar approach has identified a cohort of patients who had received routine perioperative lumbar drain placed prior to tumor resection. This has afforded the unique opportunity to analyze the comparative perioperative risks associated with this procedure. The primary goal of the current study was to determine if routine lumbar drain placement is an independent predictor of tension pneumocephalus. Secondarily, given the previously cited rationale for routine use of lumbar catheters in skull base surgery, aggregated data for all intracranial complications was assessed in relation to their placement. The secondary goal, therefore, is to determine if routine perioperative lumbar drain is associated with an altered rate of intracranial complications as a whole.

\section{MATERIALS AND METHODS}

This retrospective study was based on a review of the hospital and outpatient clinical records of a consecutive series of patients who underwent surgery of the anterior cranial base between December 1995 and November 2009. Surgical access was achieved in all cases via the transglabellar/subcranial approach (see below). All patients had either benign or malignant lesions of the anterior cranial base; cases of maxillofacial trauma were excluded from analysis. An assumption of our analysis was that degree of invasion predisposed to increased risk of intracranial complications, particularly for postoperative CSF leak. For this reason, dural and brain involvement were determined based on first-author review of imaging, operative notes, as well as pathology reports. Patient and procedure data recorded for analysis included age, gender, comorbidity, prior surgery, prior radiation, prior chemotherapy, reconstruction type, tumor histology, and surgical margins based on final pathology. Comorbidity was defined by the Diagnosis Related Group codes for fiscal year 2010 .

The transglabellar/subcranial technique has been described in detail previously. ${ }^{18}$ Briefly, wide exposure is achieved through a coronal approach, with careful preservation of a pericranial flap that is perfused by the supraorbital vessels. A frontal craniotomy is then made. Subperiosteal dissection is carried down inferiorly to completely free the superior orbit and nasal root for removal of the glabellar bar. The anterior ethmoid arteries are then ligated and divided. Vertical osteotomies are made just medial to the supraorbital notch/foramen through the superior orbital rim. Osteotomies are then carried medially along the anterior cranial fossa floor, staying anterior to the crista galli. These are continued anteriorly, inferiorly, and obliquely across the medial orbital roof and down into the nasal bones, such that they pass anterior to the anterior lacrimal crest on each side. Final osteotomies are created along the nasal bones transversely, taking care to leave approximately $3 \mathrm{~mm}$ of nasal bone distally to support the upper lateral cartilages. A sharply curved osteotome is used to separate the bony nasal septum from the supraorbital bar. Although small modifications are made depending on tumor extent, the approach consistently provides generous in-line access to the anterior cranial base while minimizing or eliminating the need for frontal lobe retraction. Nasopharyngeal airway stents are routinely placed upon completion of soft tissue closure, and the patient is extubated in the operating room. An assessment of neurologic function is performed prior to transport to the recovery unit.

Routine perioperative lumbar drain placement (i.e., prophylactic lumbar drain) was based on neurosurgeon preference and was therefore nonrandomized. Of the original 164 patients, 3 patients were excluded from analysis due to perioperative placement of a ventriculostomy. Lumbar catheter placement, if performed, was done in routine fashion between the L4 and L5 vertebrae under sterile conditions prior to scalp incision. Postoperative management of the drain was performed by the neurosurgery or neurointensive care team. Drainage is achieved via a closed continuous catheter system, which employs an intravenous fluid pump to maintain constant rates of drainage. Mean drainage volume, time until drain was clamped, and time until drain was removed were recorded.

Postoperative complications had been previously recorded and classified for the 30-day perioperative period for these patients. Patient records were reanalyzed with special focus on intracranial complications, airway management, and lumbar drain management. Intracranial complications included CSF leak, meningitis, encephalitis, stroke, intracerebral bleed, cerebral edema, and tension pneumocephalus. The diagnosis of tension pneumocephalus required all three of the following criteria: 1) clear radiographic changes on postoperative CT scan demonstrating intracranial air under pressure; 2) documented changes in neurologic function including decreased alertness, altered mental status, obtundation, or focal neurologic deficits; 3) specific documentation of the diagnosis of tension pneumocephalus. The sum total of intracranial complications for each patient and the entire sample was calculated and recorded for analysis.

Patient, perioperative, and postoperative variables were analyzed using chi-squared test for binary variables, with linear regression used for age (continuous variable). A Fisher's exact test was used when appropriate, and odds ratios were generated for each possible predictor variable. Variables identified as possible predictors of tension pneumocephalus or intracranial complications were then analyzed via binary logistic regression to identify the independent effect of each variable while controlling for the effect of possible covariates. All statistics were analyzed on SPSS for Windows version 11.01 (SPSS Inc., Chicago, IL). Statistical analysis was performed by the lead author, with additional consultation from the University of Michigan Center for Statistical Consultation and Research. The study protocol was approved by our university's institutional review board.

\section{RESULTS}

Figure 1 lists the histology of the lesions treated. There was a wide variety of tumor types, with the majority being malignant (104 of 161 , or $65 \%$ ). Table I lists the type and frequency of intracranial complications. Postoperative CSF leak was the most common complication, occurring in $18(11.2 \%)$ patients. Tension pneumocephalus (criteria listed above) occurred in five patients overall, a frequency of $3.1 \%$. Table II lists the summary data for lumbar drain management. Overall, a conservative 


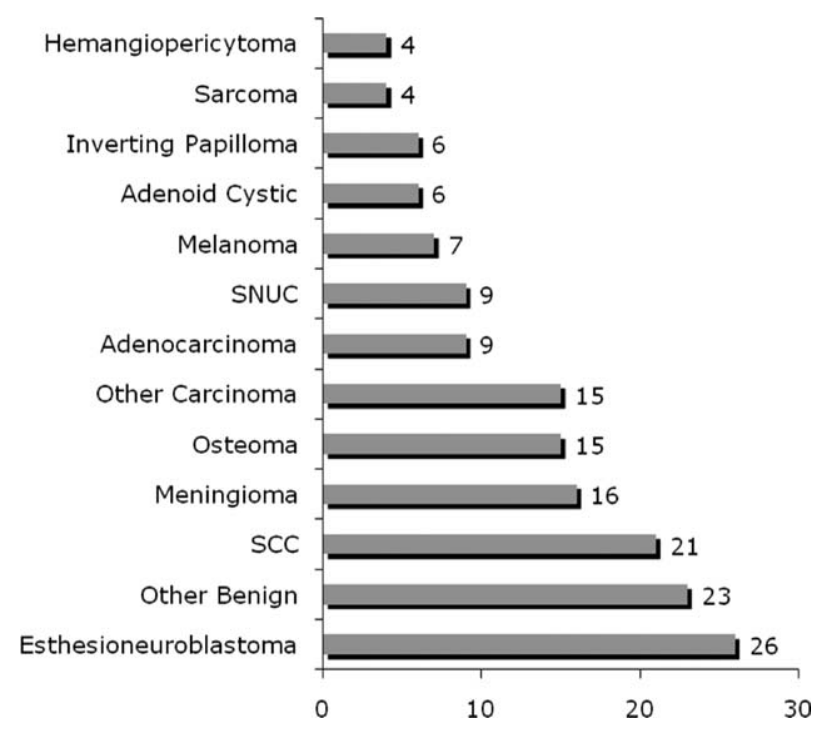

Fig. 1. Pathology for all lesions $(n=161): 104$ malignancies, 57 benign lesions. "Other carcinoma" includes mucoepidermoid carcinoma, basal cell carcinoma of the nasolacrimal duct, Papillary Schneiderian carcinoma, myoepithelial carcinoma, poorly differentiated carcinoma of lacrimal sac, and one metastatic Hurthle cell tumor. "Other benign" lesions include encephalocele, meningocele, arteriovenous malformation, ameloblastoma, cholesterol granuloma, schwannoma, null cell pituitary adenoma, chondromyxoid fibroma, and ossifying fibroma.

amount of postoperative drainage was employed, with nearly all patients having volumes $<10 \mathrm{cc} / \mathrm{hr}$. Drains were clamped 24-28 hours prior to removal, allowing for a window of clinical monitoring. Table III displays data that compares the cohort of patients that received perioperative lumbar drain versus the group that did not. There were no statistically significant differences between the patients who received prophylactic lumbar drains versus those that did not for any of the variables tested. To identify which variables predispose to tension pneumocephalus and intracranial complication, each variable was analyzed for its effect on tension pneumocephalus (Table IV) and total intracranial complications (Table V). As shown, perioperative lumbar drain was a significant predictor for

TABLE I.

Type and Frequency of Intracranial Complications in the Perioperative Period Following Subcranial Approach for Anterior Skull Base Lesions.

\begin{tabular}{lc}
\hline \multicolumn{1}{c}{ Complication } & $\mathrm{N}(\%)$ \\
\hline Total intracranial complications & $34^{\star}$ \\
CSF Leak & $18(11.2 \%)$ \\
Meningitis & $4(2.5 \%)$ \\
Encephalitis & 0 \\
Tension pneumocephalus & $5(3.1 \%)$ \\
Cerebral edema & $4(2.5 \%)$ \\
Cerebrovascular accident & 0 \\
Intracranial hematoma & $2(1.2 \%)$ \\
Total number of patients & 161 \\
\hline \hline
\end{tabular}

*Thirty-four total intracranial complications occurred in 26 patients. Seven patients had $>1$ intracranial complication.
TABLE II.

Summary Data of the Postoperative Management of the Lumbar Drains for Patients Receiving Routine Insertion of Lumbar Drain Prior to Resection of Anterior Skull Base Lesion via Subcranial Approach.

\begin{tabular}{lc}
\hline \multicolumn{1}{c}{ Variable } & Mean (SD) \\
\hline Total perioperative lumbar drains & 45 \\
Mean drainage volume (cc/hr) & $5.26( \pm 2.90)$ \\
Mean time to drain clamp (days) & $3.45( \pm 1.77)$ \\
Mean time to drain catheter removal (days) & $4.65( \pm 1.63)$ \\
\hline \hline
\end{tabular}

Note that a closed continuous drainage system was used with an intravenous fluid pump set at the desired hourly rate. Height of the system relative to the patient does not therefore affect drainage pressure. $\mathrm{SD}=$ standard deviation.

both tension pneumocephalus and intracranial complications as a whole. Placement of a lumbar drain was the only perioperative variable that was significantly associated with the occurrence of tension pneumocephalus

\section{TABLE III.}

Comparison of Perioperative and Patient Variables Between the Cohort Who Underwent Routine Perioperative Lumbar Drain and the Group That Did Not Undergo Routine Drain Placement.

\begin{tabular}{|c|c|c|c|c|}
\hline $\begin{array}{l}\text { Patient and } \\
\text { Perioperative } \\
\text { Variables }\end{array}$ & Overall n & $\begin{array}{l}\text { No Perioperative } \\
\text { Lumbar } \\
\text { Drain (\%) }\end{array}$ & $\begin{array}{l}\text { Perioperative } \\
\text { Lumbar Drain } \\
\text { Placed (\%) }\end{array}$ & $P$-Value \\
\hline Age (mean) & 48.51 & 48.64 & 48.18 & $\mathrm{NS}^{*}$ \\
\hline \multicolumn{5}{|l|}{ Gender } \\
\hline Female & 62 & $44(37.9)$ & $18(40.0)$ & \multirow[t]{2}{*}{ NS } \\
\hline Male & 99 & $72(62.1)$ & $27(60.0)$ & \\
\hline \multicolumn{5}{|l|}{ Comorbidity } \\
\hline No & 76 & $52(44.8)$ & $24(53.3)$ & \multirow[t]{2}{*}{ NS } \\
\hline Yes & 85 & $64(55.2)$ & $21(46.7)$ & \\
\hline \multicolumn{5}{|c|}{ Previous surgery } \\
\hline No & 106 & $78(67.2)$ & $28(62.2)$ & \multirow[t]{2}{*}{ NS } \\
\hline Yes & 55 & $38(32.8)$ & $17(37.8)$ & \\
\hline \multicolumn{5}{|c|}{ Previous radiotherapy } \\
\hline No & 139 & $99(85.3)$ & $40(88.9)$ & \multirow[t]{2}{*}{ NS } \\
\hline Yes & 22 & $17(14.7)$ & $5(11.1)$ & \\
\hline \multicolumn{5}{|c|}{ Dural involvement } \\
\hline No & 113 & $82(70.7)$ & $31(68.9)$ & \multirow[t]{2}{*}{ NS } \\
\hline Yes & 48 & $34(29.3)$ & $14(31.1)$ & \\
\hline \multicolumn{5}{|c|}{ Brain involvement } \\
\hline No & 146 & $106(91.4)$ & $40(88.9)$ & \multirow[t]{2}{*}{ NS } \\
\hline Yes & 15 & $10(8.6)$ & $5(11.1)$ & \\
\hline \multicolumn{5}{|l|}{ Malignancy } \\
\hline Benign & 58 & $41(35.3)$ & $17(37.8)$ & \multirow[t]{2}{*}{ NS } \\
\hline Malignant & 103 & $75(64.7)$ & $28(62.2)$ & \\
\hline \multicolumn{5}{|c|}{ Free flap reconstruction } \\
\hline No & 129 & $94(81.0)$ & 35 (77.8) & \multirow[t]{2}{*}{ NS } \\
\hline Yes & 32 & $22(19.0)$ & $10(22.2)$ & \\
\hline \multicolumn{5}{|c|}{ Surgical margins ${ }^{\dagger}$} \\
\hline Negative & 129 & $93(81.0)$ & $36(80.0)$ & \multirow[t]{2}{*}{ NS } \\
\hline Positive & 31 & 22 (19.0) & $9(20.0)$ & \\
\hline
\end{tabular}

*Linear regression analysis for continuous variable (age); all other variables analyzed via Pearson chi-square test.

${ }^{\dagger}$ Final path margins were not available for one patient. This patient was therefore excluded from analysis of this variable. 
TABLE IV.

Analysis of Patient and Perioperative Variables as Predictors of Tension Pneumocephalus.

\begin{tabular}{|c|c|c|c|c|}
\hline $\begin{array}{l}\text { Patient and } \\
\text { Perioperative } \\
\text { Variables }\end{array}$ & Overall $n$ & $\begin{array}{c}\text { Tension } \\
\text { Pneumocephalus } \\
\mathrm{n}(\%)\end{array}$ & $\begin{array}{l}\text { Odds Ratio } \\
(95 \% \mathrm{Cl})\end{array}$ & $P$ - Value \\
\hline \multicolumn{5}{|l|}{ Lumbar drain } \\
\hline No & 116 & $1(0.9)$ & $\begin{array}{c}11.220 \\
(1.218-103.314)\end{array}$ & $.022^{*}$ \\
\hline Yes & 45 & $4(8.9)$ & & \\
\hline \multicolumn{5}{|c|}{ Dural involvement } \\
\hline No & 113 & $3(2.7)$ & $\begin{array}{c}1.594 \\
(0.258-9.859)\end{array}$ & NS \\
\hline Yes & 48 & $2(4.2)$ & & \\
\hline \multicolumn{5}{|l|}{ Comorbidity } \\
\hline No & 76 & $4(5.3)$ & $\begin{array}{c}0.214 \\
(0.023-1.961)\end{array}$ & NS \\
\hline Yes & 85 & $1(1.2)$ & & \\
\hline \multicolumn{5}{|c|}{ Previous surgery } \\
\hline No & 106 & $2(1.9)$ & $\begin{array}{c}3.000 \\
(0.486-18.514)\end{array}$ & NS \\
\hline Yes & 55 & $3(5.5)$ & & \\
\hline \multicolumn{5}{|c|}{ Previous radiotherapy } \\
\hline No & 139 & $5(3.6)$ & NA & NS \\
\hline Yes & 22 & $0(0)$ & & \\
\hline \multicolumn{5}{|c|}{ Brain involvement } \\
\hline No & 146 & $4(2.7)$ & $\begin{array}{c}2.536 \\
(0.265-24.277)\end{array}$ & NS \\
\hline Yes & 15 & $1(6.7)$ & & \\
\hline \multicolumn{5}{|l|}{ Malignancy } \\
\hline Benign & 58 & $2(3.4)$ & $\begin{array}{c}0.840 \\
(0.136-5.178)\end{array}$ & NS \\
\hline Malignant & 103 & $3(2.9)$ & & \\
\hline \multicolumn{5}{|c|}{ Free flap reconstruction } \\
\hline No & 129 & $4(3.1)$ & $\begin{array}{c}1.008 \\
(0.109-9.340)\end{array}$ & NS \\
\hline Yes & 32 & $1(3.1)$ & & \\
\hline \multicolumn{5}{|c|}{ Surgical margins $^{\dagger}$} \\
\hline Negative & 129 & $4(3.1)$ & $\begin{array}{c}1.042 \\
(0.112-9.661)\end{array}$ & NS \\
\hline Positive & 31 & $1(3.2)$ & & \\
\hline Surgeon & 5 & - & - & NS \\
\hline $\begin{array}{l}\text { Drainage rate } \\
\text { (cc/hr) }\end{array}$ & 5.26 & & & \\
\hline TP & 4.81 & - & - & NS \\
\hline No TP & 5.32 & & & \\
\hline
\end{tabular}

$\mathrm{Cl}=$ confidence interval; TP $=$ tension pneumocephalus

*Fisher's exact test was employed for interpretation of the chi-square test due to the low incidence of the outcome variable $(x<10)$.

${ }^{\dagger}$ Final path margins were not available for one patient. This patient was therefore excluded from analysis of this variable.

(Table IV). Both lumbar drain and dural invasion were predictive of intracranial complication (Table V). To calculate the independent effects of the two variables on tension pneumocephalus and intracranial complications, a binary logistic regression was performed (Table VI). This confirmed perioperative lumbar drain as an independent predictor of both tension pneumocephalus and total intracranial complications when statistically controlling for the effect of dural invasion on outcome.

\section{DISCUSSION}

Tension pneumocephalus is a relatively infrequent complication of anterior skull base surgery, but can have severe clinical consequences if not recognized and treated promptly. Onset of tension pneumocephalus is often heralded by nonspecific neurologic changes such as headache, lethargy, confusion, or agitation, and less commonly by focal neurological deficits. ${ }^{10-14}$ Unrecognized tension pneumocephalus can progress to brainstem herniation due to mass effect. ${ }^{10}$ The fact that some of the early neurologic changes may be subtle or nonspecific in the setting of a recent skull base surgery underscores the importance of early extubation to allow for frequent early clinical assessment. Airway diversion via prolonged endotracheal intubation is therefore not part of our routine practice.

The pathogenesis of tension pneumocephalus has been classically explained via two different models. The "ballvalve" mechanism describes air accumulation through a skull base defect that serves as a one-way valve. Positive pressure, such as sneezing or coughing, will thereby cause entrance of atmospheric gas that has no route for egress from an otherwise intact calvarium. ${ }^{20,21}$ The inverted bottle theory, on the other hand, explains tension pneumocephalus as a byproduct of CSF drainage. CSF drainage through a lumbar catheter establishes a pressure gradient whereby the evacuated CSF is replaced by equivalent air volumes through a skull base defect. ${ }^{21}$ The two mechanisms are by no means mutually exclusive. The end result is the accumulation of a volume of air under tension that exerts a mass effect on the adjacent parenchyma. ${ }^{11}$

The diagnosis of tension pneumocephalus is a distinct clinical entity from isolated postoperative pneumocephalus. The frequency of simple pneumocephalus after craniotomy has been measured as high as $66 \%$ to $100 \%$, depending on the radiographic criteria. ${ }^{22}$ Studies focusing specifically on anterior cranial base surgery have cited rates of pneumocephalus after craniofacial resection to be in the range of $16 \%$ to $31 \% .^{9,13}$ In addition to the neurologic signs and symptoms discussed above, a commonly cited radiographic feature associated with tension pneumocephalus is subdural air compressing and separating the frontal lobes at the superior sagittal fissure (the "Mount Fuji sign"). ${ }^{12}$ The presence of air pockets in the basal cisterns has been cited as indirect evidence of a subdural air collection as well. ${ }^{12}$ It is therefore important to adhere to strict diagnostic criteria when estimating the frequency of tension pneumocephalus. The criteria used in this study (neurologic signs or symptoms, radiographic changes, and attending neurosurgeon diagnosis) were therefore designed to be highly specific for true tension pneumocephalus so as to improve our ability to detect possible causative factors.

The rates of tension pneumocephalus following anterior craniofacial resection vary from approximately $1 \%$ to $7 \% .^{3-9}$ Recent reports assert that airway diversion via aggressive means (i.e., prolonged intubation or prophylactic tracheostomy) may not reduce rates of tension pneumocephalus, at least in such frequency that is easily measured. ${ }^{15}$ At our institution, we insert nasopharyngeal airways following skin closure and eschew prophylactic tracheostomy or prolonged intubation for airway diversion. Although nasopharyngeal airways have been promoted as effective 
TABLE V.

Analysis of Patient and Perioperative Variables as Predictors of Intracranial Complications as an Aggregate Value.

\begin{tabular}{|c|c|c|c|c|}
\hline $\begin{array}{l}\text { Patient and } \\
\text { Perioperative } \\
\text { Variables }\end{array}$ & Overall $n$ & $\begin{array}{c}\text { Intracranial } \\
\text { Complications } \\
\mathrm{n}(\%)\end{array}$ & $\begin{array}{l}\text { Odds Ratio } \\
(95 \% \mathrm{Cl})\end{array}$ & $P$-Value \\
\hline \multicolumn{5}{|l|}{ Lumbar drain } \\
\hline No & 116 & $14(12.2)$ & $\begin{array}{c}2.623 \\
(1.104-6.233)\end{array}$ & $.025^{\star}$ \\
\hline Yes & 45 & $12(26.7)$ & & \\
\hline \multicolumn{5}{|c|}{ Dural involvement } \\
\hline No & 113 & $12(10.6)$ & $\begin{array}{c}3.571 \\
(1.503-8.484)\end{array}$ & $.003^{*}$ \\
\hline Yes & 48 & $14(29.8)$ & & \\
\hline \multicolumn{5}{|l|}{ Comorbidity } \\
\hline No & 76 & $9(12.0)$ & $\begin{array}{c}1.833 \\
(0.763-4.403)\end{array}$ & NS \\
\hline Yes & 85 & $17(20.0)$ & & \\
\hline \multicolumn{5}{|c|}{ Previous surgery } \\
\hline No & 106 & $14(13.2)$ & $\begin{array}{c}1.878 \\
(0.800-4.406)\end{array}$ & NS \\
\hline Yes & 55 & $12(22.2)$ & & \\
\hline \multicolumn{5}{|c|}{ Previous radiotherapy } \\
\hline No & 139 & $21(15.2)$ & $\begin{array}{c}1.639 \\
(0.545-4.923)\end{array}$ & NS \\
\hline Yes & 22 & $5(22.7)$ & & \\
\hline \multicolumn{5}{|c|}{ Brain involvement } \\
\hline No & 146 & $21(14.5)$ & $\begin{array}{c}2.952 \\
(0.917-9.502)\end{array}$ & NS \\
\hline Yes & 15 & $5(33.3)$ & & \\
\hline \multicolumn{5}{|l|}{ Malignancy } \\
\hline Benign & 58 & $11(19.3)$ & $\begin{array}{c}0.713 \\
(0.303-1.678)\end{array}$ & NS \\
\hline Malignant & 103 & $15(14.6)$ & & \\
\hline \multicolumn{5}{|c|}{ Free flap reconstruction } \\
\hline No & 129 & $21(16.4)$ & $\begin{array}{c}0.944 \\
(0.326-2.731)\end{array}$ & NS \\
\hline Yes & 32 & $5(15.6)$ & & \\
\hline \multicolumn{5}{|c|}{ Surgical margins $^{\dagger}$} \\
\hline Negative & 129 & $19(14.7)$ & $\begin{array}{c}1.698 \\
(0.638-4.466)\end{array}$ & NS \\
\hline Positive & 31 & 7 (22.6) & & \\
\hline Surgeon & 5 & - & - & NS \\
\hline $\begin{array}{l}\text { Drainage rate } \\
\text { (cc/hr) }\end{array}$ & 5.26 & & & \\
\hline ICC & 4.97 & - & - & NS \\
\hline No ICC & 5.38 & & & \\
\hline
\end{tabular}

prophylaxis for tension pneumocephalus, existing studies have been insufficiently powered to prove this relationship given the relative rarity of the complication. ${ }^{17}$ We plan a dedicated study to elucidate the role of nasopharyngeal airway stents in complication prophylaxis. The current study does not include a group that underwent anterior skull base surgery without postoperative airway stent insertion that may be used for comparison.
The transglabellar/subcranial approach augments the inferior exposure of a frontal craniotomy, eliminating or greatly reducing the need for frontal lobe retraction. ${ }^{3}$ In theory, this may likewise decrease the need for routine lumbar drainage. Analogous results were reported by Solero et al., ${ }^{8}$ in their series of anterior skull base tumors. They progressively moved craniotomy sites more inferiorly over the course of their series. The low craniotomy enabled them to perform the procedure with less retraction of the parenchyma. The authors felt that this obviated the need for perioperative lumbar drain. They noted significantly lower complication rates after switching to more inferior craniotomy sites and minimizing routine use of lumbar catheters for CSF drainage.

One of the possible benefits of placing a lumbar drain prior to resection is that it may aid in decompressing the dura and improve access for resection. ${ }^{6,7}$ Lumbar drains are also assumed to decompress the dural repair, thereby reducing the incidence of delayed CSF fistula. ${ }^{16}$ There is no clear consensus in the literature on the complication rate of routine placement of a lumbar catheter for CSF drainage in anterior skull base surgery. One of the most frequently cited studies by Roland et al. ${ }^{23}$ calculates a $12.5 \%$ rate of major complication of CSF drainage following surgery on the posterior cranial fossa; the rate of minor complication was 59\%. Of the severe complications reported, these include tension pneumocephalus, meningitis, and transtentorial herniation. ${ }^{24,25}$ However, several studies have concluded that, in general, closed continuous lumbar drainage of cerebrospinal fluid in the perioperative setting is a safe practice. ${ }^{23,25}$ The patient undergoing surgery on the anterior cranial base, however, is subject to unique risks. The proximity of the air-filled paranasal sinuses and the challenges of reconstructing this region have led some authors to advocate caution in employing lumbar catheters on a routine basis. ${ }^{26}$

Given that perioperative lumbar drain placement has been shown to decrease rates of CSF leak in surgery on the posterior cranial fossa, ${ }^{16}$ a secondary goal of this study was to measure intracranial complications as an aggregate. It could be possible that although lumbar drain predisposes to tension pneumocephalus, the overall rate of intracranial complication may be reduced. We failed to find such an effect, and instead found evidence to the contrary (Table V). Routine use of perioperative lumbar drain was predictive of higher rates of intracranial complications, despite no

TABLE VI.

Binary Logistic Regression of Possible Cofactors That Predict Tension Pneumocephalus and Intracranial Complication.

\begin{tabular}{llc}
\hline \multicolumn{1}{c}{ Predictor } & $\begin{array}{c}\text { Tension Pneumocephalus } \\
(P \text {-Value, Odds Ratio [CI] })\end{array}$ & $\begin{array}{c}\text { All Intracranial } \\
\text { Complications }(P \text {-Value, } \\
\text { Odds Ratio [Cl] })\end{array}$ \\
\hline $\begin{array}{c}\text { Perioperative } \\
\text { lumbar drain }\end{array}$ & $P=.033$, OR & $P=.040$, OR 2.55 \\
Dural involvement & NS & $P=.17$ [1.21-1.02.95-6.22] \\
& & {$[1.64-9.39]$} \\
\hline \hline
\end{tabular}

The predictive value of perioperative lumbar drain on the outcomes tension pneumocephalus and intracranial complication was significant. This significance was maintained when controlling for the effect of dural invasion on outcome. Note that dural involvement and perioperative lumbar drain are both independent predictors of intracranial complication. 
TABLE VII.

Post Hoc Analysis of Rates of CSF Leak for the Cohort That Received Perioperative Lumbar Drains versus Those That Did Not.

\begin{tabular}{|c|c|c|c|c|}
\hline & Overall $n$ & CSF Leak n (\%) & Odds Ratio (95\% Cl) & $P$-Value \\
\hline \multicolumn{5}{|c|}{ Lumbar drain } \\
\hline No & 116 & $12(10.3)$ & NS & NS \\
\hline Yes & 45 & 6 (13.3) & & \\
\hline
\end{tabular}

There was no significant reduction in the rates of postoperative CSF leak in the group that had standard perioperative lumbar drain placed. The rates of dural invasion, brain invasion, and malignancy did not differ between these two groups (see Table II).

$\mathrm{CSF}=$ cerbral spinal fluid; $\mathrm{Cl}=$ confidence interval.

difference in preoperative and perioperative variables between the two groups (Table III). Additionally, a post hoc analysis of our sample was performed to compare the rates of CSF leak in the cohort of patients who received perioperative lumbar drain versus those who did not. Perioperative lumbar drain did not reduce the rate of CSF leaks in the postoperative period following subcranial surgery (Table VII). As shown, the rates of delayed CSF leak were similar between patients who had received a perioperative drain (13.3\%), versus those who did not (10.4\%). The fact that routine perioperative lumbar drain was predictive of higher rates of intracranial complications is likely due in part to the fact that drain placement did not appear to diminish the risk of delayed CSF leak.

The relative infrequency of tension pneumocephalus makes it difficult to obtain sufficient sample sizes to perform statistical analysis. This is a large series of patients with a cohort that received routine perioperative lumbar drain prior to subcranial surgery. This afforded a unique opportunity to identify the causative factors of a rare complication. The retrospective and nonrandomized nature of the study are the chief limitations. Despite a thorough review of the medical records and existing literature, it is possible that there are additional perioperative variables that may be predictive of intracranial complication that were not included in these analyses. In addition, the cohort that received routine perioperative lumbar drain was treated from 1995 to 2001 . This is the earlier segment of our study period, and may confound the analysis. The total intracranial complication rate for that time period (1995-2001) was $23 \%$. By comparison, the total intracranial complication rate from 2002 to 2009 was $13 \%$. It is therefore possible that the lower rate of total intracranial complications in the more recent study period could be due to greater familiarity with the procedure, and not the decreased use of routine lumbar drainage. This is an inherent difficulty with retrospective control groups.

The reasons for the change in our operative protocol also deserve mention. One neurosurgeon who routinely inserted lumbar drains left the institution. It should be noted, however, that there was no effect of surgeon on the rate of tension pneumocephalus (Table IV) or total intracranial complications (Table V). Other participating neurosurgical faculty reported decreasing the routine use of lumbar catheters due to concerns for tension pneumocephalus, as discussed above.

As with any single institution review of anterior skull base lesions, key determinants of clinical outcome include tumor histology, extent of disease, as well as operative techniques and perioperative protocols. These are rarely consistent between large-scale retrospective series. Despite this, the results presented above appear relevant to all surgical approaches to the anterior skull base, from advanced endoscopic approaches to traditional anterior craniofacial resection.

\section{CONCLUSION}

In a retrospective cohort, routine perioperative lumbar drain placement was associated with a significantly increased risk of tension pneumocephalus and total intracranial complications following anterior skull base surgery.

\section{BIBLIOGRAPHY}

1. Dulgerov P, Jacobsen MS, Abdelkarim SA, et al. Nasal and paranasal sinus carcinoma: are we making progress? Cancer 2001;92:312-329.

2. Gil Z, Patel SG, Bilsky M, et al. Complications after craniofacial resection for malignant tumors: are complication trends changing? Otolaryngol Head Neck Surg 2009;140:218-223.

3. Deschler DG, Gutin PH, Mamelak AN, et al. Complications of anterior skull base surgery. Skull Base Surg 1996;6:113-118.

4. Kraus DH, Shah JP, Arbit E, et al. Complications of craniofacial resection for tumors involving the anterior skulll base. Head Neck 1994;16:307-312.

5. Ganly I, Patel SG, Singh B, et al. Complications of craniofacial resection for malignant tumors of the skull base: report of an International Collaborative Study. Head Neck 2005;27:445-451.

6. Donald PJ. Complications in skull base surgery for malignancy. Laryngoscope 1999;109:1959-1066.

7. Dias FL, Geraldo MS, Kligerman J, et al. Complications of anterior craniofacial resection. Head Neck 1999;21:12-20.

8. Solero CL, DiMeco F, Sampath P, et al. Combined anterior craniofacial resection for tumors involving the cribriform plate: early postoperative complications and technical considerations. Neurosurgery 2000;47:1296-1304.

9. Richtsmeier WJ, Briggs RJ, Koch WM, et al. Complications and early outcome of anterior craniofacial resection. Arch Otolaryngol Head Neck Surg 1989:101:665-669.

10. Schirmer CM, Heilman CB, Bhardwaj A. Pneumocephalus: case illustrations and review. Neurocrit Care 2010;13:152-158.

11. Clevens RA, Marentette LJ, Esclamado RM, Wolf GT, Ross DA. Incidence and management of tension pneumocephalus after anterior craniofacial resection: case reports and review of the literature. Otolaryngol Head Neck Surg 1995;120:579-583.

12. Ishiwata Y, Fujitsu K, Sekino T, Fujino H, Kubokura T, Tsubone K, Kuwabara T. Subdural tension pneumocephalus following surgery for chronic subdural hematoma. J Neurosurg 1988;68:58-61.

13. Yates H, Hamill M, Borel CO, Toung TJ. Incidence and perioperative management of tension pneumocephalus following craniofacial resection. $J$ Neurosurg Anesthesiol 1994;6:15-20.

14. Wanamaker JR, Mehle ME, Wood BG, Lavertu P. Tension pneumocephalus following craniofacial resection. Head Neck 1995;17:152-156.

15. Gil Z, Cohen JT, Spektor S, et al. Anterior skull base surgery without prophylactic airway diversion procedures. Otolaryngol Head Neck Surg 2003;128:681-685.

16. Bien AG, Bowdino B, Moore G, Leibrock L. Utilization of preoperative cerebrospinal fluid drain in skull base surgery. Skull Base 2007;17:133-139.

17. Lewis CM, Lin DT, Curry WT, et al. The use of nasopharyngeal airways for airway diversion in anterior craniofacial resection. Am J Rhinol 2008;22:529-532.

18. Kellman RM, Marentette LJ. The transglabellar/subcranial approach to the anterior skull base. Arch Otol Head Neck Surg 2001;127:687-690.

19. Raveh J, Vuillemin T, Sutter F. Subcranial management of 395 combined fontobasal-midface fractures. Arch Otol Head Neck Surg 1988;114:1114-1122.

20. Walker FO, Vern BA. The mechanism of pneumocephalus formation in patients with CSF fistulas [sic]. J Neurol Neurosurg Psychol 1986;49:203-205.

21. Lunsford LD, Maroon JC, Sheptak PE, Albin MS. Subdural tension pneumocephalus. Report of two cases. J Neurosurg 1979;50:525-527.

22. Reasoner DK, Todd MM, Scamman FL, Warner DS. The incidence of pneumocephalus after supratentorial craniotomy. Observations on the disappearance of intracranial air. Anesthesiology 1994;80:1008-1012.

23. Roland PS, Marple BF, Meyerhoff WL, et al. Complications of lumbar spinal fluid drainage. Otolaryngol Head Neck Surg 1992;107:564-569.

24. Mirza S, Saeed SR, Ramsden RT. Extensive tension pneumocephalus complicating continuous lumbar CSF drainage for the management of CSF rhinorrhea. ORL J Otorhinolaryngol Relat Spec 2003;65:215-218.

25. Acikbas SC, Akyuz M, Kazan S, Tuncer R. Complications of closed continuous lumbar drainage of cerebrospinal fluid. Acta Neurochir (Wien) 2002;144:475-480.

26. Kryzanski JT, Annino DJ, Heilman CB. Complication avoidance in the treatment of -malignant tumors of the skull base. Neurosurg Focus $2002 ; 12: 1-6$ 